\title{
Sol-Gel Thin Films Immobilized with Bromocresol Purple pH-Sensitive Indicator in Presence of Surfactants
}

\author{
Nizam M. El-Ashgar, ${ }^{1}$ Ahmed I. El-Basioni, ${ }^{1}$ Issa M. El-Nahhal, ${ }^{2}$ Shehata M. Zourob, ${ }^{2}$ \\ Taher M. El-Agez, ${ }^{3}$ and Sofyan A. Taya ${ }^{3}$ \\ ${ }^{1}$ Department of Chemistry, The Islamic University of Gaza, P.O. Box 108, Gaza, Palestine \\ ${ }^{2}$ Department of Chemistry, Al-Azhar University, P.O. Box 1277, Gaza, Palestine \\ ${ }^{3}$ Department of Physics, The Islamic University of Gaza, P.O. Box 108, Gaza, Palestine
}

Correspondence should be addressed to Nizam M. El-Ashgar, nashgar@iugaza.edu.ps

Received 11 November 2011; Accepted 7 December 2011

Academic Editors: N. Chaniotakis, I. Djerdj, and J. Zieba-Palus

Copyright ( 2012 Nizam M. El-Ashgar et al. This is an open access article distributed under the Creative Commons Attribution License, which permits unrestricted use, distribution, and reproduction in any medium, provided the original work is properly cited.

Preparation of transparent sol-gel thin film immobilized with bromocresol purple (BCP) pH-sensitive indicator was made via the acid catalyzed sol-gel reaction of tetraethylorthosilicate and the bromocresol purple indicator (BCP). Different surfactants include cationic cetyl trimethyl ammonium bromide (CTAB), anionic sodium dodecyl sulfate (SDS), and nonionic Triton X-100 (TX-100) were used to improve the mesostructure of the host material and to increase its porosity. The color change behavior of the immobilized bromocresol purple indicator affected significantly in presence of SDS comparing with its free counterpart in aqueous solution. In presence of CTAB and Triton-X 100, the immobilized bromocresol purple indicator shows similar behavior as its free counterpart in aqueous solution. The BCP retains its structure during the sol-gel reactions in terms of response to $\mathrm{pH}$. Different parameters including concentration of indicator and surfactant, temperature, number of layers, response time, life time, and the number of measurements were investigated. The $\mathrm{p} K_{a}$ values of the different prepared BCP immobilized thin films were determined. The BCP thin film sensor showed stability, repeatability, reproducibility, fast response, and long life time behavior. The polarized light microscopy indicated that the bromocresol purple indicator molecules are distributed uniformly within the host silica network.

\section{Introduction}

Preparation of sol-gel matrices doped with some chemically and biologically active molecules is a promise route to chemical solid-state sensors [1-4]. The sol-gel technique is one of the most promising tools in material science. The term sol-gel refers to a chemical process where metallic or semimetallic alkoxide precursors or their derivatives form composites at moderate temperatures through a chemical reaction that involves hydrolysis followed by polycondensation [2]. Hydrolysis and polycondensation of tetraethoxysilane in presence of water, organic solvent, and an acid/base catalyst result in the formation of the $-\mathrm{Si}-\mathrm{O}-\mathrm{Si}-$ threedimensional siloxane network [3-5]. The resulting matrix has high surface area, porosity, inertness, and stability to chemical and physical agents, and optical clarity in the visible and UV ranges [6-8]. Sol-gel matrices appear as a very important technique for immobilization, entrapment, encapsulation for large variety of materials such as organic, inorganic, and biomolecules $[9,10]$. The sol-gel materials are ideal candidates as hosts for the analytical reagents because they are synthesized at low concentrations at the ambient temperature $[11,12]$.

A wide variety of organic molecules and complexes have been proved as dopants for sensing purposes [13]. The low temperature of the sol-gel method, porosity of material formed and high surface area of host matrix favor the use of a wide range of organic dyes. The entrapment of $\mathrm{pH}$ sensitive dyes into such inorganic host porous materials using solgel processing has received considerable attention over the past few years [14-16]. The entrapped $\mathrm{pH}$-sensitive materials often retain their activity and functionality to large extent. 
The porosity of sol-gel matrices allows diffusion of active material and reactants. Through these reactions, the $\mathrm{pH}-$ sensitive materials possess sensing ability to detect the $\mathrm{pH}$ of solutions. The $\mathrm{pH}$ indicators were chemically or physically immobilized into a solid support [17-20]. Silica is considered as one of the best solid substrate used to host the $\mathrm{pH}$ indicators.

The sol-gel process could be controlled comparing to conventional sol-gel process under proper conditions. Subsequently, active $\mathrm{pH}$-sensitive molecules are added to the sol medium, and as the inorganic three-dimensional network develops, the active material and the residue solvents are expelled from the growing network and finally trapped into network cages [21-23]. A relatively long period of time, for example, few weeks, can then cause solvent evaporation to obtain active-molecules, doped, transparent, and dried matrix [14]. Surfactants were used considerably in recent years to form mesostructures of silica matrix and so high porosity silica was obtained that host sensing molecules efficiently $[12,13,22]$. Recently sol-gel thin films were useful to encapsulate many active molecules such as inorganic clusters, porphyrins, photochromic and laser dyes, rare earth complexes, bioactive molecules, and so forth, that were mainly obtained for sensing purposes [6-15].

There are three methods of indicator immobilization in sol-gel include impregnation, covalent binding and chemical doping. Many pH-sensing materials immobilized into solid supports have been reported $[12,13,22]$. The effects of the silica matrix and presence of surfactants on the $\mathrm{pH}$ response and $\mathrm{p} K_{a}$ were well documented for many $\mathrm{pH}$ sensitive doped systems $[13,22]$. In this work, the spin-coating method was used for the immobilization of bromocresol purple $\mathrm{pH}$-indicator in presence of cationic CTAB, anionic SDS, and nonionic TX-100 surfactants. The active materials and their $\mathrm{pH}$ response behavior were characterized using UV-Vis spectroscopy and optical polarized microscopy.

\section{Experimental}

2.1. Chemicals and Reagents. Tetraethylorthosilicate $\mathrm{Si}(\mathrm{OEt})_{4}$ (TEOS), bromocresol purple $\mathrm{C}_{21} \mathrm{H}_{16} \mathrm{Br}_{2} \mathrm{O}_{5} \mathrm{~S}$ (BCP), sodiumdodecylsulfate $\mathrm{C}_{12} \mathrm{H}_{25} \mathrm{SO}_{4} \mathrm{Na}$ (SDS), cetyltrimethylammonium bromide $\mathrm{C}_{19} \mathrm{H}_{42} \mathrm{BrN}$ (CTAB), Triton-X $100 \mathrm{C}_{14} \mathrm{H}_{22} \mathrm{O}\left(\mathrm{C}_{2} \mathrm{H}_{4} \mathrm{O}\right)_{n}$ (TX-100), hydrochloric acid, sodium hydroxide, and absolute ethanol were purchased from Merck (Darmstadt, Germany). All chemicals were used as received without further purifications.

\subsection{Thin Film Preparation}

2.2.1. Preparation of Hydrolyzed TEOS. A mixture of $2.5 \mathrm{~mL}$ of absolute $\mathrm{MeOH}, 0.5 \mathrm{~mL}$ of $0.1 \mathrm{M}$ of $\mathrm{HCl}$, and $2.5 \mathrm{~mL}$ of water were added to $5 \mathrm{~mL}$ of TEOS under stirring. The obtained solution was kept under stirring at room temperature until a homogeneous clear solution was obtained. The solution was aged at least for 24 hours before being used in the coating process. The hydrolyzed TEOS solution was used as a host matrix for the indicators.
2.2.2. Preparation of Indicator and Surfactants Solutions. Different concentrations of BCP indicator $(0.05,0.01,0.001$, 0.0001 , and $0.00001 \mathrm{M}$ ) in ethanol were prepared. Cationic CTAB, anionic SDS, and non-ionic TX-100 of different concentrations $(0.05,0.01,0.001,0.0001$ and $0.00001 \mathrm{M})$ were prepared in ethanol.

2.2.3. Sample and Blank Solutions. Two types of sample solutions containing BCP indicator were prepared. The first was prepared by mixing $1 \mathrm{~mL}$ of hydrolyzed TEOS and $1 \mathrm{~mL}$ of bromocresol purple (BCP). The other was prepared by mixing $1 \mathrm{~mL}$ of hydrolyzed TEOS, $0.5 \mathrm{~mL}$ of CTAB, SDS or TX-100, and $1 \mathrm{~mL}$ of bromocresol purple (BCP). Two blank solutions (indicator free) of pure hydrolyzed TEOS and hydrolyzed TEOS/surfactant $(2: 1, \mathrm{v} / \mathrm{v}$ resp.) were prepared. The surfactants used were CTAB, SDS, or TX-100.

2.2.4. Thin Films Deposition. A glass microscope slides $(2.5 \mathrm{~cm} \times 0.8 \mathrm{~cm} \times 1 \mathrm{~mm})$ were pretreated before film deposition. The glass slides were treated with concentrated nitric acid for 2 hours, washed with water and ethanol then dried at $120^{\circ} \mathrm{C}$ for two hours. All thin films layers prepared were done by spinning a $100 \mu \mathrm{L}$ of the mention coating solutions onto the clean glass slides. The coating process was performed using the spin coater machine at $1900 \mathrm{rpm}$ spinning speed and 25 seconds time period. The obtained wet coated layers were let to dry at $40^{\circ} \mathrm{C}$ for 24 hours followed by drying at $80^{\circ} \mathrm{C}$ for another 48 hours. To obtain multilayers of thin films a subsequent spin-coating method was performed after gradually oven-drying the previous layer for 72 hours at $80^{\circ} \mathrm{C}$. These films were washed several times with methanol/deionized water. The washes were collected in order to examine the leaching percentage of the added indicator from the films. Characterization was investigated using UV/Vis spectrophotometer and polarization light microscopy techniques.

2.2.5. UV/Vis Spectrophotometer. The optical absorption spectra of the coating solutions and the deposited films were obtained by using a single-beam GENESYS $10 \mathrm{UV}$ Scanning Spectrophotometer in the range (190-1100 nm) of automatical rotation. Coated slides were placed along the wall of the sample cell and exposed to different $\mathrm{pH}$ solutions (1-13.5).

2.2.6. Polarization Light Microscopy. The surface morphology of the films was characterized by using a zeiss Standard polarization microscope model BX50 equipped with an Olympus Dp-100 camera attachment.

\section{Results and Discussion}

Glass slides have been coated with bromocresol purple (BCP) $\mathrm{pH}$ indicator through spin-coating process. The substrate was spinned at a controlled speed where the sol was spread onto the substrate. The preparation method is summarized in the following steps: 


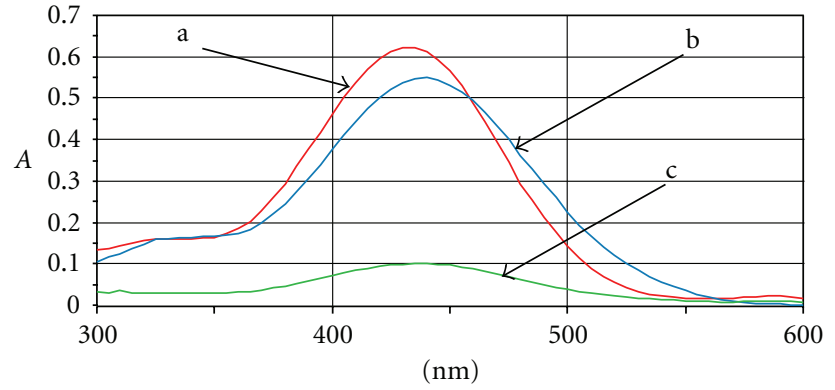

Figure 1: Absorption spectra of (a) free BCP, (b) immobilized $\mathrm{BCP} / \mathrm{SDS}$ and (c) immobilized BCP without surfactant.

(a) hydrolysis of tetraethylorthosilicate by water at room temperature in ethanol; hydrochloric acid was used as a catalyst;

(b) addition of $\mathrm{BCP} \mathrm{pH}$ indicator of different concentrations in the presence or absence of surfactant;

(c) Preparation of transparent thin film using spincoating technique.

Different factors are considered to influence the monolithicity of the silica disks including amount of solvent, concentration of catalyst, amount of added ingredients, and number of cover's pores. Ionic surfactants CTAB, SDS, and nonionic surfactant TX-100 were used to modify the monolithic thin film silica structure.

\subsection{UV/Vis Spectra of the Free and Immobilized BCP. The $\mathrm{pH}$} range of BCP at normal conditions occurs at $\mathrm{pH} 5.2$ (yellow color) and at pH 6.8 (purple color) which correspond to the absorption bands at $433 \mathrm{~nm}$ and $591 \mathrm{~nm}\left(\lambda_{\max }\right)$, respectively and its $\mathrm{p} K_{a}$ value is 6.3 .

The absorption spectra for the free $\mathrm{BCP}$, immobilized $\mathrm{BCP}$, and immobilized BCP/SDS at the range of 300$700 \mathrm{~nm}$, in water, are given in Figure 1. The spectrum of the immobilized BCP exhibits an absorption peak at $440 \mathrm{~nm}$ with a red shift of about $7 \mathrm{~nm}$ compared with the free BCP. This implies that the BCP molecules are probably physically interacted into the silica network (Scheme 1). The spectrum of the immobilized BCP/SDS shows stronger absorption band at $435 \mathrm{~nm}$ than that of the immobilized BCP without surfactant (Figure 1). The reason for this behavior is that the presence of SDS has modified the silica network structure and may increase its porosity and therefore increase the surface area.

3.2. Effect of Concentration of $B C P$. Different concentrations of BCP $(0.00001,0.0001,0.001,0.01,0.05 \mathrm{M})$ in presence of SDS were used to investigate the effect of amount of indicator trapped within the thin film on absorption capacity. The sol mixture by volume ratio was $1: 1: 0.5$ of $\mathrm{BCP}:$ hydrolyzed TEOS : surfactant, respectively. The trapped BCP thin films were examined versus the absorbance at $\lambda_{\max }=435 \mathrm{~nm}$ (Figure 2). The absorbance increases with increasing concentration of added $\mathrm{BCP}$ and reaches its maximum at $0.05 \mathrm{M}$. At

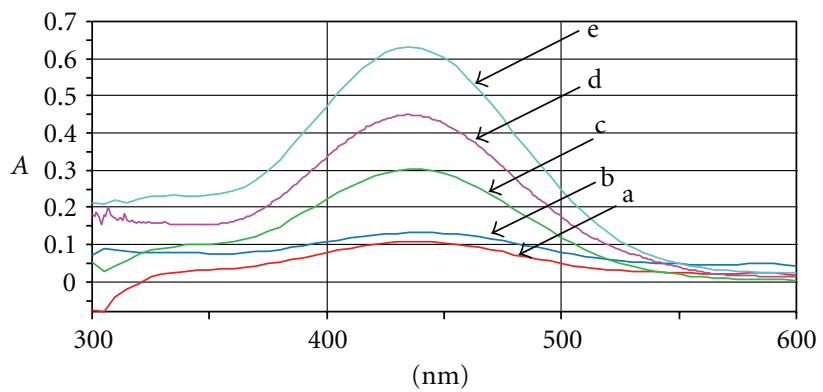

FIGURE 2: Absorption spectra of immobilized BCP/SDS at different concentrations of BCP: (a) $0.00001 \mathrm{M}$, (b) $0.0001 \mathrm{M}$, (c) $0.001 \mathrm{M}$ (d) $0.01 \mathrm{M}$, and (e) $0.05 \mathrm{M}$.

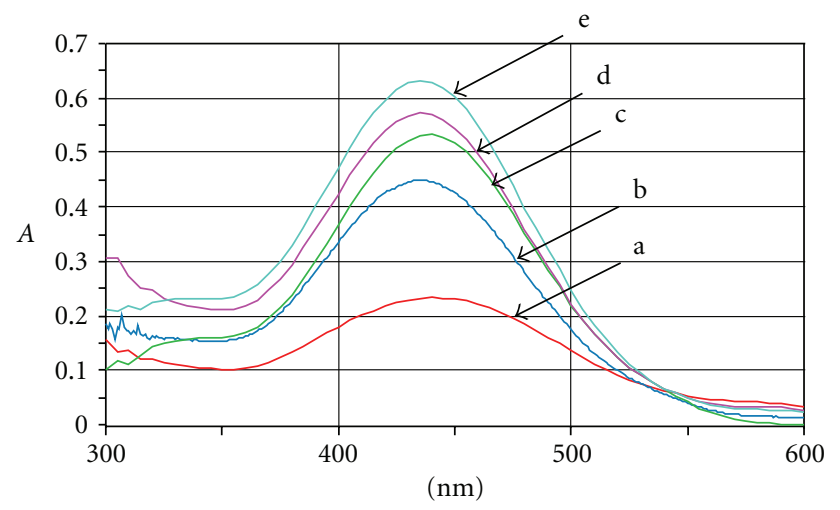

FIGURe 3: Absorption spectra of immobilized BCP/SDS at different concentrations of SDS: (a) $0.00001 \mathrm{M}$, (b) $0.0001 \mathrm{M}$, (c) $0.001 \mathrm{M}$ (d) $0.01 \mathrm{M}$, and (e) $0.05 \mathrm{M}$.

high concentration of BCP $(>0.05 \mathrm{M})$ precipitation occurred. These results imply that the number of binding sites available for the indicator increases with concentration.

3.3. Effect of Concentration of Surfactants. Different concentrations of SDS, CTAB, or T-X $100(0.00001-0.05 \mathrm{M})$ which were trapped with BCP $(0.05 \mathrm{M})$, were prepared and examined versus the absorbance at $\lambda_{\max }=430-435 \mathrm{~nm}$. Figure 3 depicted the effect of SDS concentration on the absorbance of BCP thin films as an example. It is shown that the absorbance is increased with increasing concentration of surfactant and reaches its maximum at $0.05 \mathrm{M}$. Similar results were obtained in case of CTAB and T-X 100 surfactants. These results imply that the number of binding sites available for the surfactants increases with concentration. Surfactant concentration that are higher than $0.05 \mathrm{M}$ lead to cracking in the films.

3.4. Comparison between Surfactants. The absorption spectra of the immobilized BCP within the sol-gel matrix thin films with and without surfactant are given in Figure 4 . Three different surfactants were used to examine their effect on loading capacity of BCP. It was observed that absorption increases in the following order:

$$
\begin{aligned}
\mathrm{BCP} / \mathrm{SDS} & >\mathrm{BCP} / \mathrm{CTAB}>\mathrm{BCP} / \mathrm{TX}-100 \\
& >\mathrm{BCP} / \text { without surfactant. }
\end{aligned}
$$




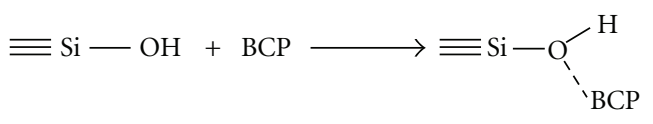

Free BCP Immobilized BCP

SCHEMe 1

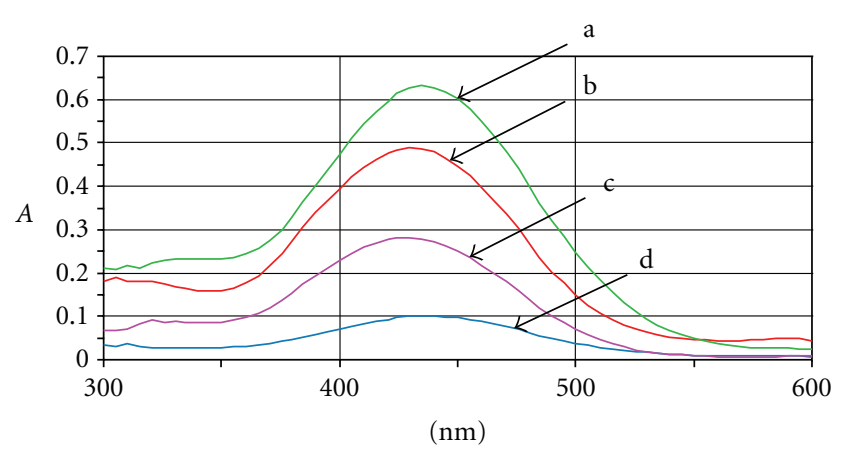

FIGURE 4: Absorption spectra of (a) BCP/SDS, (b) BCP/CTAB, (c) $\mathrm{BCP} / \mathrm{TX}-100$, and (d) BCP/without surfactant.

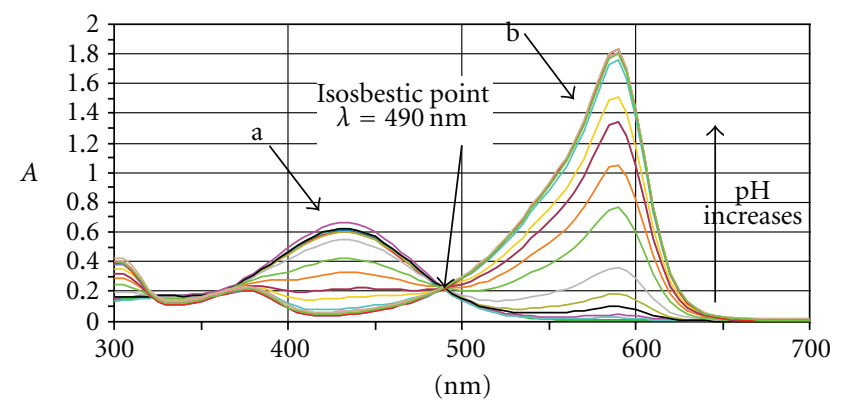

Figure 5: Absorption spectra of free BCP at different $\mathrm{pH}$ values (114): (a) $\mathrm{pH} 1-5, \lambda_{\max }=433 \mathrm{~nm}$; (b) $\mathrm{pH} 5.5-14, \lambda_{\max }=590 \mathrm{~nm}$.

The reason of this behavior is that the silica-doped BCP thin film has been modified well in the presence of SDS in comparison with the presence of CTAB or Triton X-100.

Generally the presence of surfactant modifies the structure of gel matrix and therefore the surface area increases so more BCP molecules can loaded. This was also confirmed by polarized light microscopy. The spectra show an absorption band at $440 \mathrm{~nm}$ for immobilized BCP in absence of surfactant. A main absorption band occurred at $435 \mathrm{~nm}$ for $\mathrm{BCP} / \mathrm{SDS}$, while the BCP/TX-100 and BCP/CTAB showed an absorption band at $430 \mathrm{~nm}$.

3.5. UV-Vis Spectra of Immobilized BCP versus $p H$. The UV-Vis absorption spectrum of free BCP $\left(5 \times 10^{-5} \mathrm{M}\right)$ treated with different $\mathrm{pH}$ solutions $(\mathrm{pH}=1-14)$ is shown in Figure 5. Two absorption bands were clearly observed with the presence of one indicating transition at $\mathrm{pH} 1-14$. The isosbestic point at this transition occurs at $490 \mathrm{~nm}$. These bands are due to acidic (yellow) and basic (purple) colors (Scheme 2), which observed at 433 and $590 \mathrm{~nm}$ respectively.

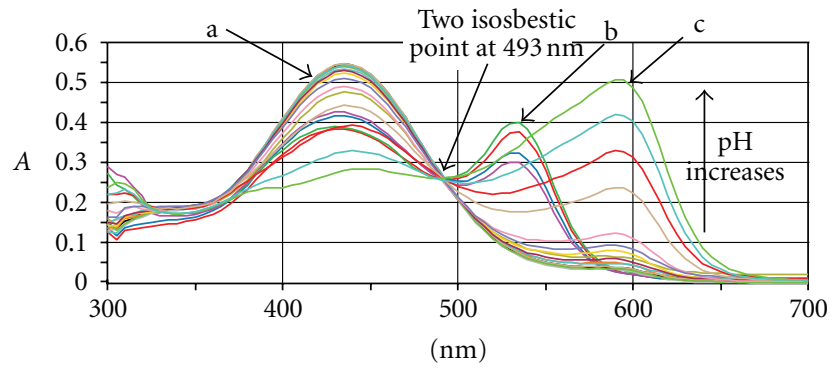

FIGURE 6: Absorption spectra of immobilized BCP/SDS at different $\mathrm{pH}$ values (1-13.5): (a) $\mathrm{pH} 1-10, \lambda_{\max }=435 \mathrm{~nm}$, (b) $\mathrm{pH} 1-4.5, \lambda_{\max }$ $=535 \mathrm{~nm}$, and (c) $10.5-13.5, \lambda_{\max }=595 \mathrm{~nm}$.

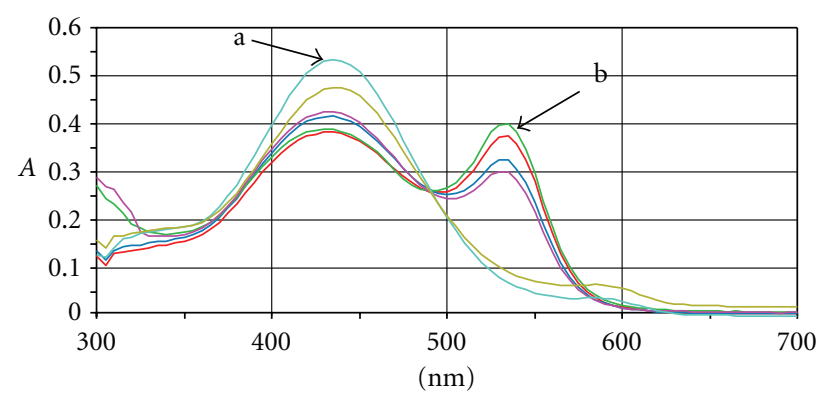

FIGURE 7: Absorption spectra of immobilized BCP/SDS at pH 14.5: (a) $\lambda_{\max }=435 \mathrm{~nm}$, and (b) $\lambda_{\max }=535 \mathrm{~nm}$.

The absorption spectra of the immobilized BCP/SDS thin film treated with different $\mathrm{pH}$ solutions $(\mathrm{pH}=1-13.5)$ are shown in Figure 6. Two indicating transitions were clearly observed as shown in the figure instead of one transition for the free BCP with the presence of two isosbestic points superimposed at $493 \mathrm{~nm}$. The first transition is due to equilibrium between acidic (yellow) form and (red) neutral form. The second transition is due to the equilibrium between the neutral (red) form and basic (purple) form. In case of treating the immobilized BCP/SDS thin film with aqueous solutions of $\mathrm{pH} 1-10.5$, two absorption bands were obtained at 435 and $535 \mathrm{~nm}$ as shown in Figure 7. It is obvious that the peak at $535 \mathrm{~nm}$ corresponds to low $\mathrm{pH}$ values $(\mathrm{pH} 1-4.5)$ and decreased significantly as $\mathrm{pH}$ increased where the peak at $435 \mathrm{~nm}$ increases. At $\mathrm{pH}$ 5-10.5 a strong absorption occurs at $435 \mathrm{~nm}$ without significant changes of absorbance while the peak at $535 \mathrm{~nm}$ is nearly disappeared (Figure 8). Above $\mathrm{pH} 10.5$ the absorbance of the peak at $435 \mathrm{~nm}$ is decreased with an increase of another peak at $595 \mathrm{~nm}$ as the $\mathrm{pH}$ increases (Figure 9). At pH 13.5 the peak at $435 \mathrm{~nm}$ was nearly disappeared. The spectrum for $\mathrm{pH}=13.5$ is the same as that of BCP in the basic solutions. 


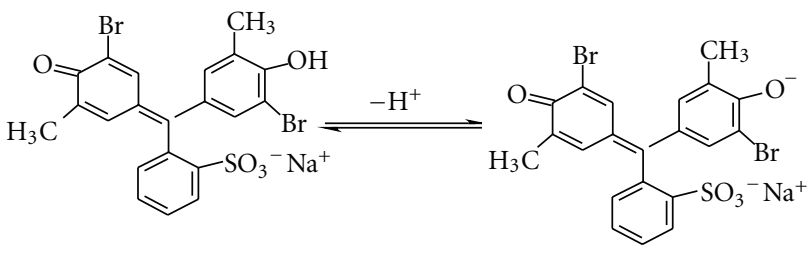

Scheme 2

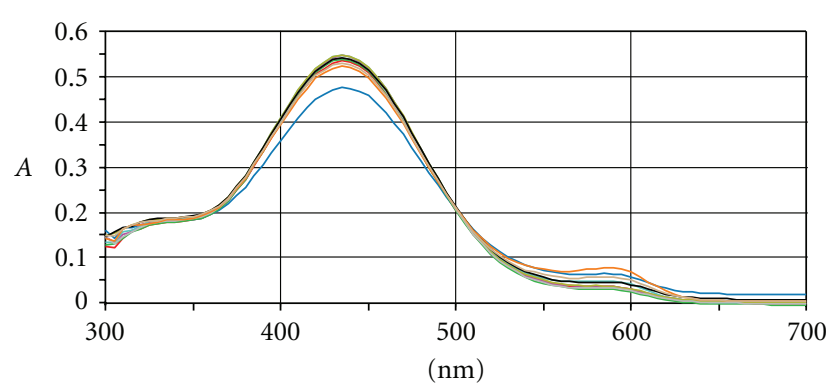

FIGURE 8: Absorption spectra of immobilized BCP/SDS at pH 5$10.5, \lambda_{\max }=435$.

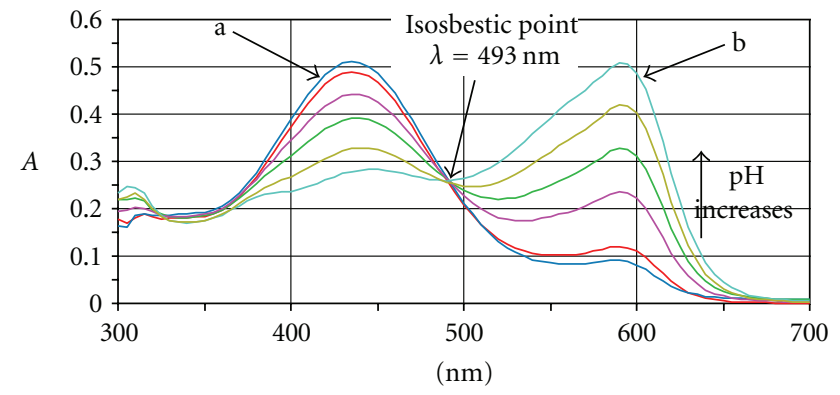

FIGURE 9: Absorption spectra of immobilized BCP/SDS at pH 1113.5: (a) $\lambda_{\max }=435 \mathrm{~nm}$, (b) $\lambda_{\max }=595 \mathrm{~nm}$.

The spectra of the immobilized BCP have a new peak that appeared at $535 \mathrm{~nm}$ at $\mathrm{pH} 1-4.5$ (Figure 6) (acidic medium) which is not found in case of free BCP in solution. This implies that an interaction between $\mathrm{BCP}$ and silica matrix takes place (Scheme 3 ).

The $\mathrm{p} K_{a 1}$ and $\mathrm{p} K_{a 2}$ values for the immobilized BCP/SDS were calculated from the absorption spectra at $\mathrm{pH}$ range (113.5) and were found 2.75 and 8.7, respectively (Figures 10 and 11 , resp.). The $\mathrm{p} K_{a 1}=2.75$ for the immobilized BCP occurs at $\mathrm{pH}$ range $1-4.5$ (Figure 10). It can be explained that in acidic medium, there were perhaps dispersive forces (weak interaction) between protonated $\mathrm{H}_{2} \mathrm{BCP}^{+}$and the silanols for the silica matrices. The increase of $\mathrm{p} K_{a 2}$ value in the $\mathrm{pH}$ range 5-10.5 (basic medium) from 6.3 for the free BCP to 8.7 for the immobilized BCP/SDS (Figure 11) is probably that in basic medium, a deprotonation of the silanols occurred, so $\equiv \mathrm{S}_{-} \mathrm{O}^{-}$species were formed and $\mathrm{BCP}^{-}$anion is more favorable. In neutral medium it is expected that a hydrogen bonding species ( $\equiv \mathrm{Si}-\mathrm{OH}-\mathrm{BCP})$ is probably formed.

The absorption spectra of the immobilized $\mathrm{BCP} / \mathrm{CTAB}$ treated with different $\mathrm{pH}$ solutions $(\mathrm{pH}=1-13.5)$ is shown in

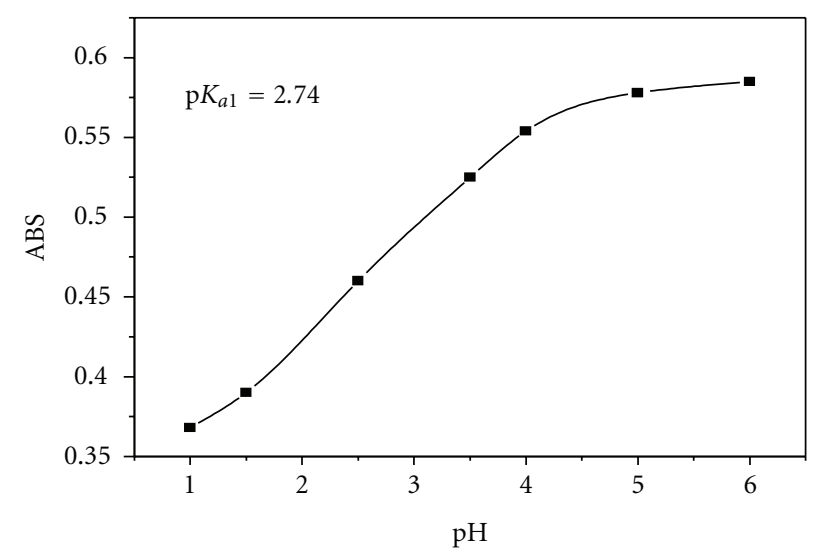

FIgURE 10: $\mathrm{p} K_{a 1}$ value of immobilized BCP/SDS.

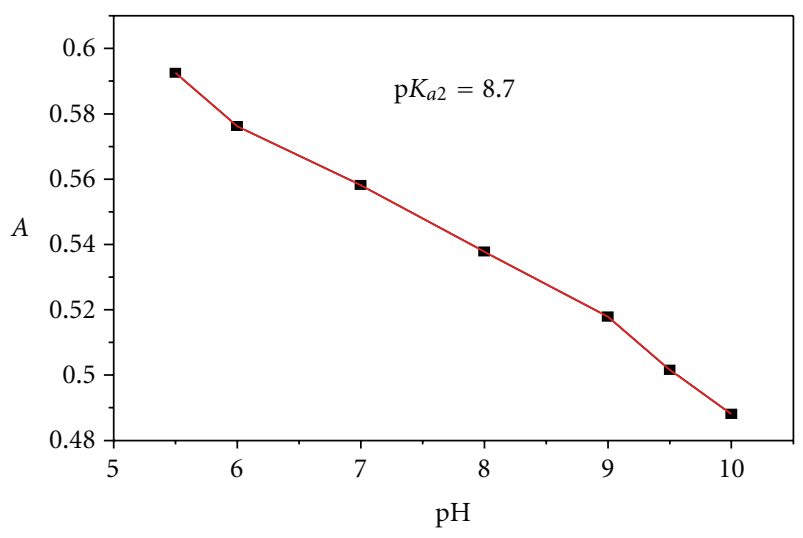

FIgURE 11: $\mathrm{p} K_{a 2}$ value of immobilized BCP/SDS.

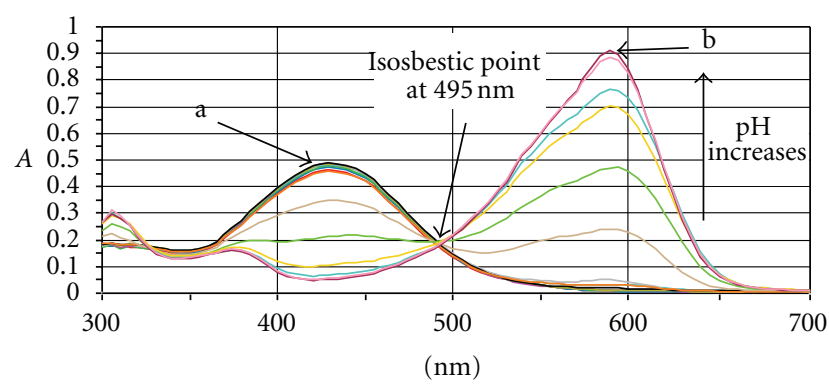

FIGURE 12: Absorption spectra of immobilized BCP/CTB at different $\mathrm{pH}$ values (1-13.5): (a) $\mathrm{pH} 1-8, \lambda_{\max }=430 \mathrm{~nm}$ and (b) $\mathrm{pH} 9$ $13.5, \lambda_{\max }=595 \mathrm{~nm}$. 


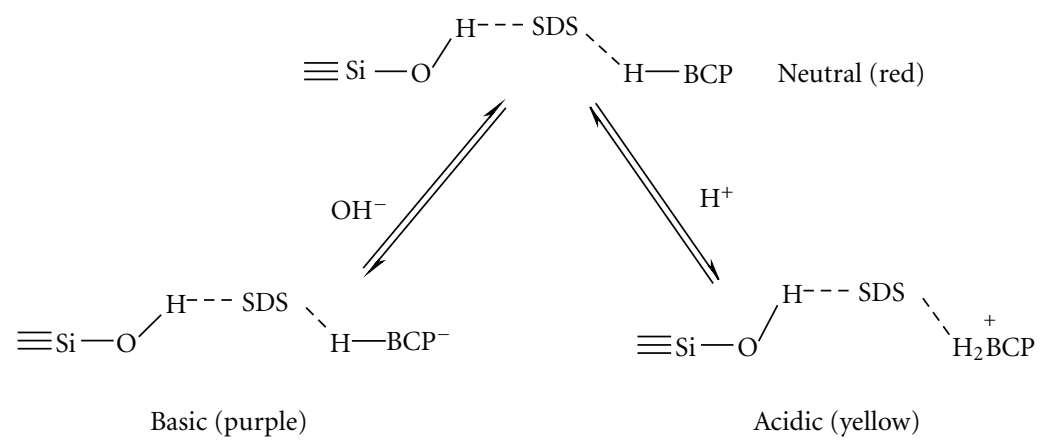

SCHEME 3

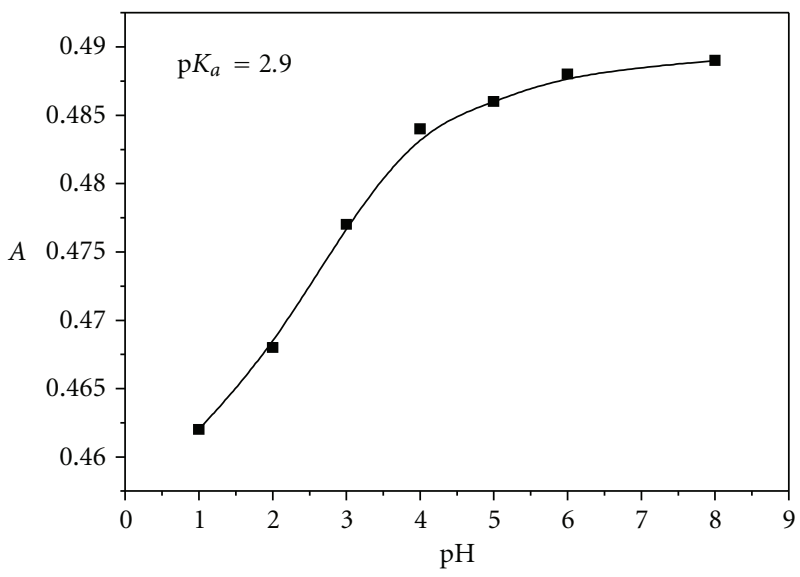

FIGURE 13: $\mathrm{p} K_{a}$ value of the immobilized BCP/CTAB.

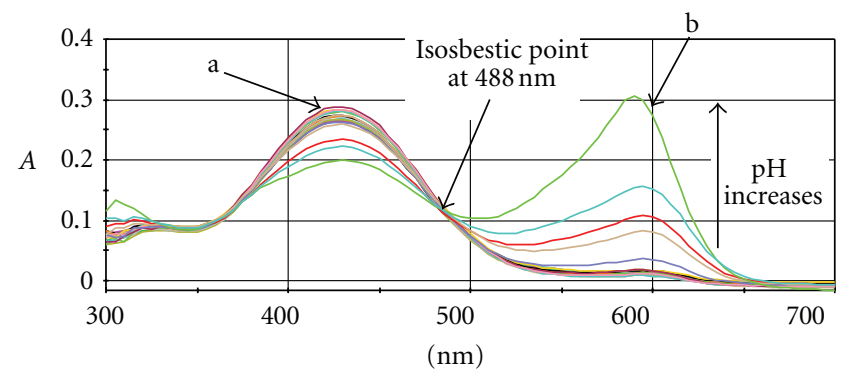

Figure 14: Absorption spectra of immobilized BCP/TX-100 at different $\mathrm{pH}$ values (1-13.5). (a) $\mathrm{pH} 1-8, \lambda_{\max }=430 \mathrm{~nm}$ and (b) $\mathrm{pH} 9-13.5, \lambda_{\max }=595 \mathrm{~nm}$.

(Figure 12). Two absorption bands were clearly observed due to acidic (yellow) and basic (purple) colors which occurs at 430 and $595 \mathrm{~nm}$, respectively. Only one transition is observed (from acidic form to basic form) upon $\mathrm{pH}$ treatment of $\mathrm{BCP} / \mathrm{CTAB}$ at $\mathrm{pH} 1-13.5$. One isosbestic point is present at $495 \mathrm{~nm}$, due to the acid base equilibrium of the two forms of BCP. At pH 1-8, a strong specific band occurs at $430 \mathrm{~nm}$ without significant changes of absorbance. Above $\mathrm{pH} 8$, as the basicicity of the solution increases, the absorbance of the peak at $430 \mathrm{~nm}$ is decreased and another peak appears at $595 \mathrm{~nm}$. This corresponds to a change from the acidic form $\mathrm{HIn}^{+}$to the basic form $\mathrm{In}^{-}$of BCP. The intensity of the peak

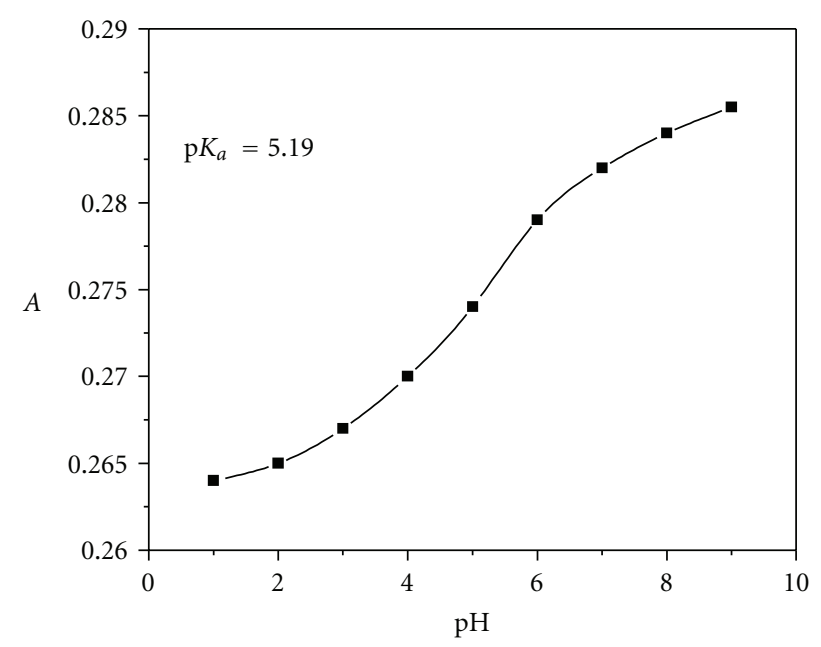

FIGURE 15: $\mathrm{p} K_{a}$ value of immobilized BCP/TX-100.

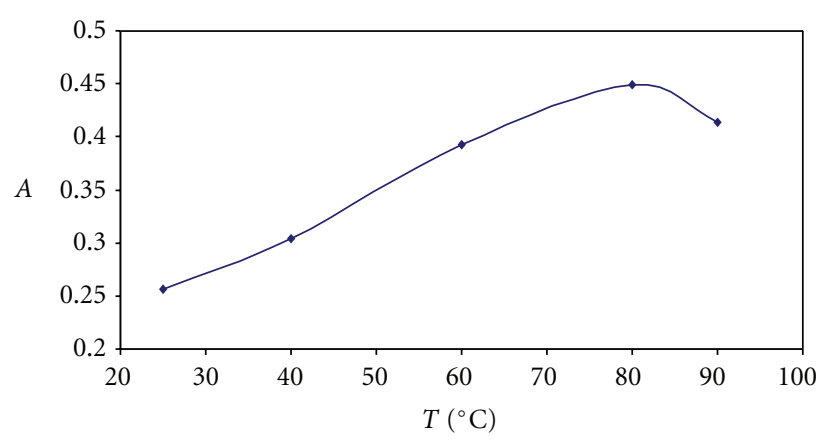

FIGURE 16: Effect of drying temperature on BCP/SDS thin film absorption spectra.

at $595 \mathrm{~nm}$ is increased with an increase in $\mathrm{pH}$ of the solutions. At $\mathrm{pH} 13.5$ the peak at $430 \mathrm{~nm}$ nearly disappeared. The spectrum for $\mathrm{pH}=13.5$ is the same as that of immobilized $\mathrm{BCP} / \mathrm{SDS}$ in the basic solutions.

The $\mathrm{p} K_{a}$ value of the immobilized BCP/CTAB was calculated from the spectra of the immobilized thin film versus $\mathrm{pH}$ and was found 6.9 (Figure 13). This value is higher than that of the free $\mathrm{BCP}\left(\mathrm{p} K_{a}=6.3\right)$ due to the interaction 


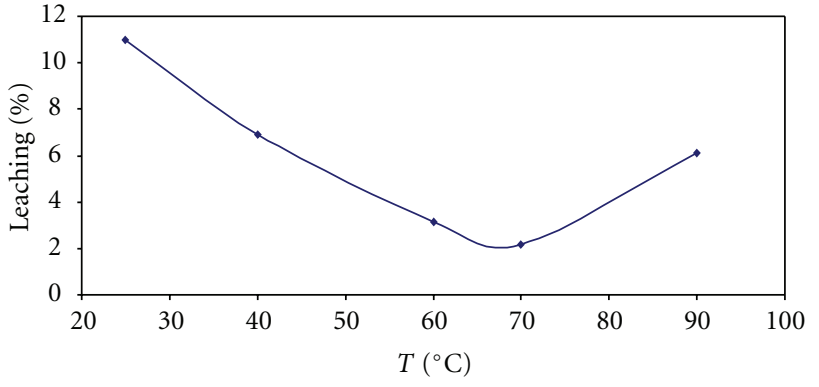

FIGURE 17: Effect of heat on BCP/SDS versus \%Leaching.

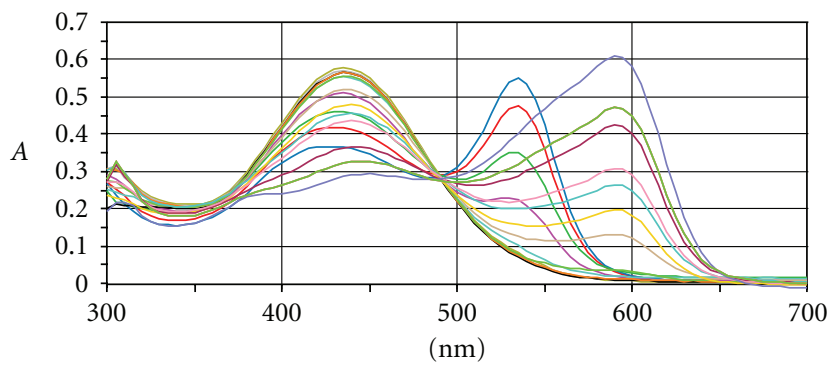

FIGURE 18: Forward absorption spectra of BCP/SDS at pH 1-13.

with CTAB which favors the anionic hydrophilic species of BCP.

The absorption spectra of the immobilized BCP/TX-100 treated with different $\mathrm{pH}$ solutions $(\mathrm{pH}=1-13.5)$ is shown in Figure 14. Two absorption bands were clearly observed due to acidic (yellow) and basic (purple) colors which occurs at 430 and $595 \mathrm{~nm}$, respectively. Only one transition is observed (from acidic form to basic form) upon $\mathrm{pH}$ treatment of $\mathrm{BCP} / \mathrm{TX}-100$ at $\mathrm{pH} 1-13.5$. One isosbestic point is present at $488 \mathrm{~nm}$, due to the acid base equilibrium of the two forms of BCP. At pH 1-8 a strong specific band occurs at $430 \mathrm{~nm}$ without significant changes of absorbance. Above $\mathrm{pH} 8$, as the basicicity of the solution increases, the absorbance of the peak at $430 \mathrm{~nm}$ is decreased and another peak appeared at $595 \mathrm{~nm}$. This corresponds to a change from the acidic form $\mathrm{HIn}^{+}$to the basic form $\mathrm{In}^{-}$of BCP. The intensity of the peak at $595 \mathrm{~nm}$ is increased with an increase in $\mathrm{pH}$ of the solutions. At $\mathrm{pH} 13.5$ the peak at $430 \mathrm{~nm}$ nearly disappeared. The spectrum for $\mathrm{pH}=13.5$ is the same as that of immobilized $\mathrm{BCP} / \mathrm{SDS}$ and immobilized $\mathrm{BCP} / \mathrm{CTAB}$ in the basic solutions.

The $\mathrm{p} K_{a}$ value of the immobilized BCP/TX-100 was calculated from the spectra of the immobilized thin film versus $\mathrm{pH}$ and was found 5.19 (Figure 15). This value is lower than that of the free $\mathrm{BCP}\left(\mathrm{p} K_{a}=6.3\right)$ (more acidic) due to protonation of $\mathrm{BCP}$ which resulted from the strong electrostatic interaction between BCP and TX-100.

3.6. Effect of Drying Temperature. The BCP thin films have been dried at different temperatures $\left(25-100^{\circ} \mathrm{C}\right)$. It was found that highest absorption occurred for samples dried at

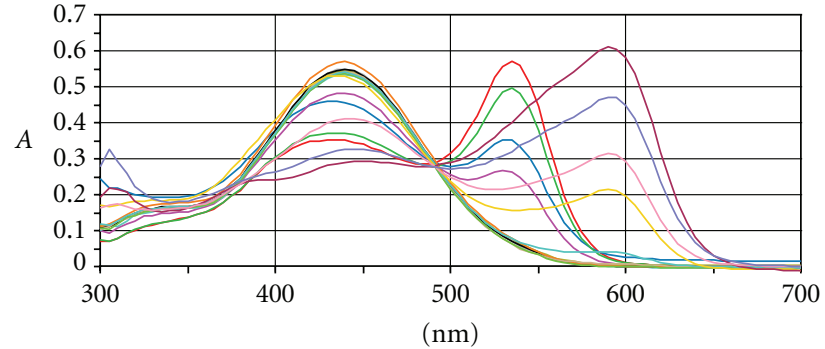

FIGURE 19: Backward absorption spectra of BCP/SDS at pH 13-1.

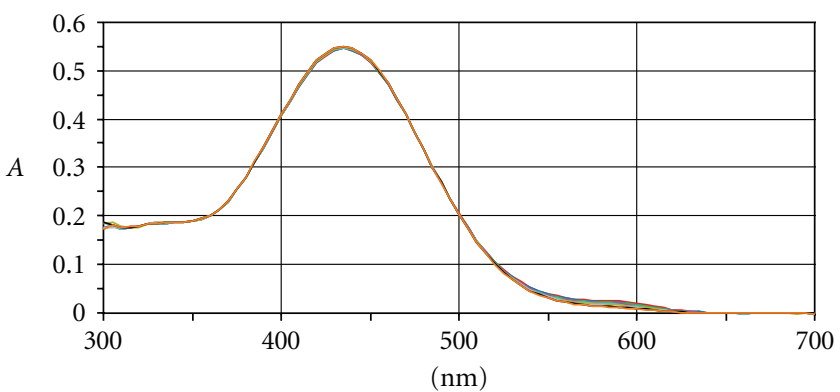

FIGURE 20: Absorption spectra of BCB/SDS for ten measurements at $\mathrm{pH} 7$.

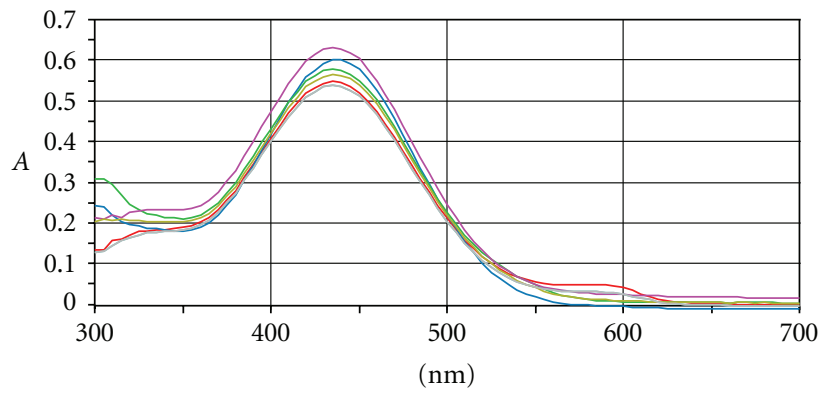

FIgure 21: Absorption spectra of seven different BCB/SDS thin films at $\mathrm{pH} 7$.

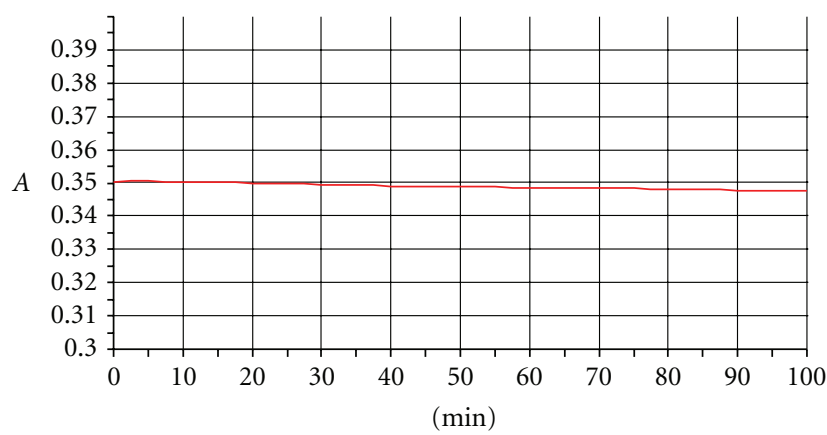

FIGURE 22: Relation between absorbance of BGP/SDS and time. 


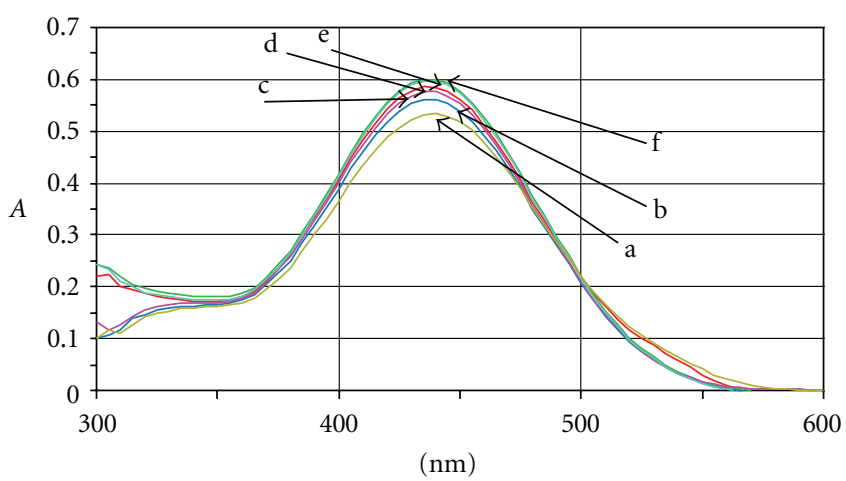

FIGURE 23: Absorption spectra of immobilized BCP/SDS at $\mathrm{pH} 7$ after immersed in $1 \mathrm{M}$ aqueous solutions of: (a) sodium hydroxide; (b) ammonium hydroxide; (c) hydrochloric acid; (d) acetic Acid; (e) potassium hydroxide; (f) distilled water.

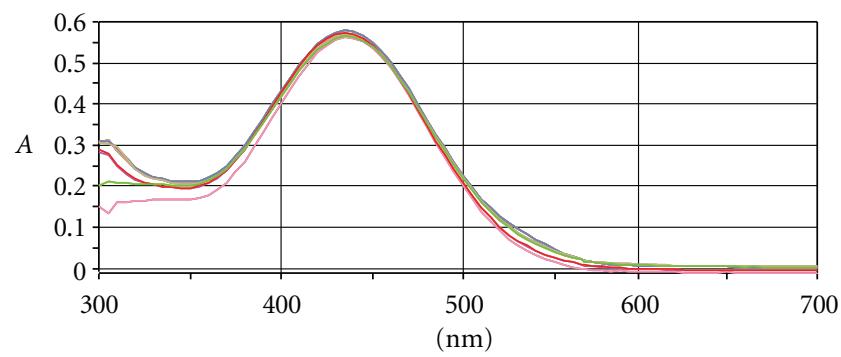

FIGURE 24: Absorption spectra of immobilized BCP/SDS within sixmonth time period of measurements at $\mathrm{pH} 7$.

$80^{\circ} \mathrm{C}$ (Figure 16). It can be explained that most of the physically absorbed water and alcohol molecules were evaporated from the pores of silica matrix when the films were dried at $80^{\circ} \mathrm{C}$. This allows $\mathrm{BCP}$ to be accommodated well within the silica pores and strongly interacted within the silica matrix. At temperatures higher than $80^{\circ} \mathrm{C}$ the absorption decreases which can be probably due to decomposition of SDS surfactant and so the thin film started cracking.

3.7. Effect of Surfactant Type and Heat on BCP Leaching. The effect of surfactant on leaching of BCP was studied. It is found that lowest leaching of BCP molecules from thin films was observed when SDS surfactant was used and when these films were dried at $80^{\circ} \mathrm{C}$ (Table 1). The reason for this is that in case of SDS a strong interaction between the BCP molecules and the anionic SDS surfactant takes place. It was found that the leaching percentage of BCP from thin film silica matrix is arranged in the following order:

$$
\begin{aligned}
\mathrm{BCP} / \mathrm{SDS} & <\mathrm{BCP} / \mathrm{TX}-100<\mathrm{BCP} / \mathrm{CTAB} \\
& <\mathrm{BCP} / \text { without surfactant. }
\end{aligned}
$$

The effect of heat on leaching of $\mathrm{BCP}$ molecules from $\mathrm{BCP} / \mathrm{SDS}$ thin films was studied and the results are given in Figure 17. It is shown that as temperature increases, the amount of $\mathrm{BCP}$ decreases up to $70^{\circ} \mathrm{C}$; after reaching this

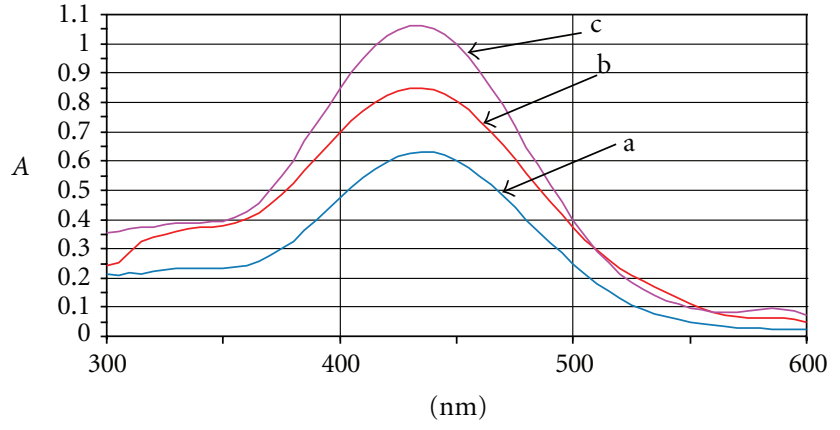

FIgURE 25: Absorption spectra of multilayer BCP/SDS thin film measured at $\mathrm{pH} 7$ : (a) single layer, (b) double layer, and (c) triple layer.

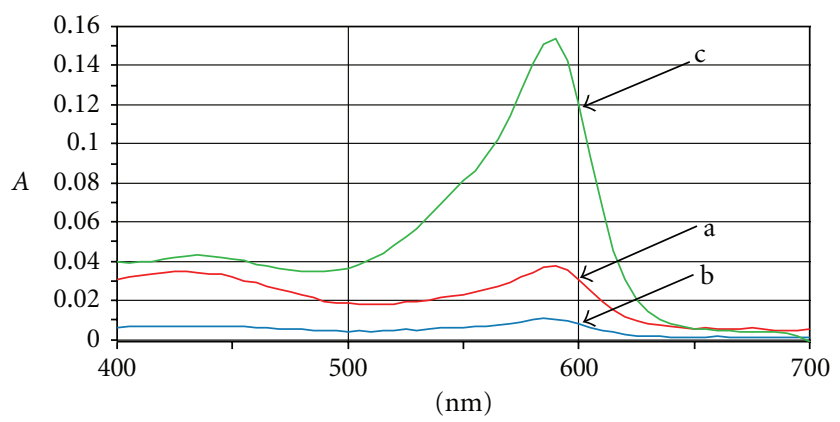

FIgURE 26: Absorption spectra of leached BCP from multilayer BCP/SDS thin film: (a) single layer, (b) double layer, and (c) triple layer.

TABLE 1: Effect of surfactant type on \% leaching of BCP.

\begin{tabular}{lc}
\hline Thin film & \% leaching \\
\hline Immobilized BCP/no surfactant & 36.60 \\
Immobilized BCP/CTAB & 17.30 \\
Immobilized BCP/TX-100 & 12.20 \\
Immobilized BCP/SDS & 2.10 \\
\hline
\end{tabular}

temperature the thin film becomes less stable and so $\mathrm{BCP}$ molecules are leached out.

3.8. BCP Sensor Reversibility. BCP thin films act as reversible sensors for $\mathrm{pH}$ changes in forward and backward directions. These spectra were obtained at $\mathrm{pH}$ ranges $1-13$ and $13-1$ in the range of $\lambda$ from $300 \mathrm{~nm}$ to $700 \mathrm{~nm}$ and are given in Figures 18 and 19, respectively.

3.9. BCP Sensor Repeatability and Reproducibility. Repeatability of BCS sensor was studied by conducting ten cycles measurement using BCP/SDS thin film. The cycles were repeated within 24 hours to check stability of the BCP $\mathrm{pH}$ sensor on repeating measurements. It is found that the absorbance after each measurement remains almost 


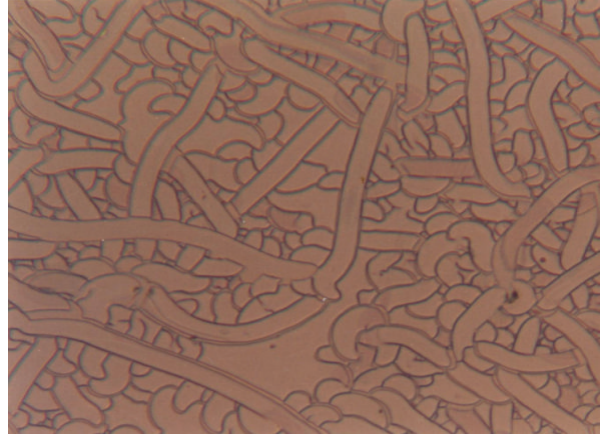

(a)

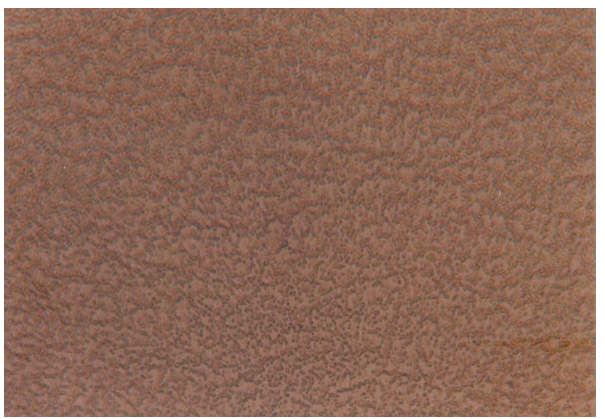

(c)

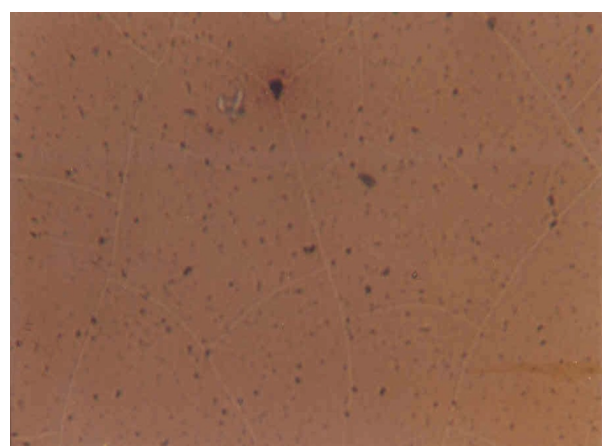

(b)

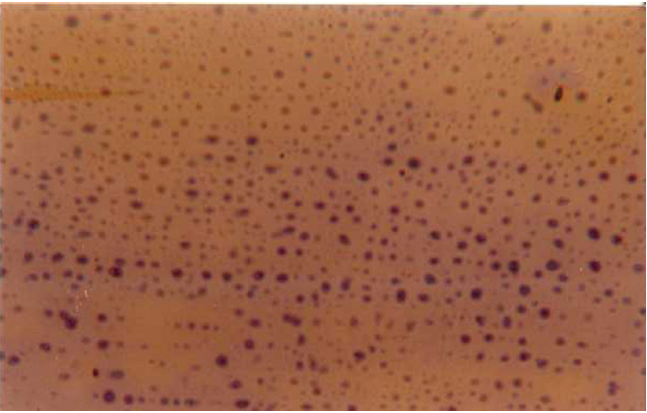

(d)

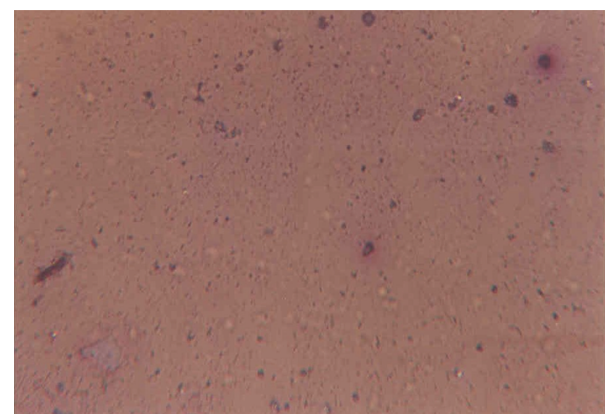

(e)

FIGURE 27: (a) PLM photograph of the free silica thin film, (b) PLM photograph of immobilized BCP thin film without surfactant, (c) PLM photograph of the immobilized BCP/SDS thin film, (d) PLM photograph of immobilized BCP/CTAB thin film, (e) PLM photograph of immobilized BCP/TX-100 thin film.

unchanged over the $\mathrm{pH}$ range 1-13. Absorbance of the repeatability measurements was performed at $435 \mathrm{~nm}(\mathrm{pH}$ $1-10)$ and at $595 \mathrm{~nm}$ (pH 11-13). Figure 20 shows the absorbance versus number of measurements at $\mathrm{pH}$ 7. The absorbance is nearly constant. The standard deviation and $\%$ relative standard deviations of 10 repeated measurements at pH 7 within 24 hours are 0.002 and 0.36 , respectively. Similar results were observed for repeating measurements at $\mathrm{pH}$ range $1-13$. The standard deviation and percentage relative standard deviation ranges for ten repeated measurements for different $\mathrm{pH}$ values were zero-0.036 and zero-5.45, respectively (Table 2 ). This promises that BCP/SDS thin films can be used as a good $\mathrm{pH}$ sensor without degradation during repeated measurements at $\mathrm{pH}$ range $1-13$.
The sensor reproducibility was also studied by performing seven independent preparations of BCP/SDS thin films using the same method of preparation and testing their capacity sensing. Figure 21 shows the absorbance of seven different prepared films at $\lambda_{\max }=435 \mathrm{~nm}$ at $\mathrm{pH}$ 7. Results given in Figure 21 showed good agreement and stability for all the prepared thin films.

3.10. Response Time. Figure 22 shows the relation between absorbance and response time for BCP/SDS thin film at $\lambda_{\max }=435 \mathrm{~nm}$. It is observed that the the thin film is highly sensitive to color change. This is explained by the availability of BCP molecules for the active $\mathrm{pH}$ ingredients 
TABLE 2: BCP sensor repeatability.

\begin{tabular}{lccc}
\hline $\mathrm{pH}$ & $\begin{array}{c}\text { Number of } \\
\text { measurements }\end{array}$ & SD & $\%$ RSD \\
\hline 1 & 10 & 0.0055 & 1.37 \\
2 & 10 & 0.0150 & 3.33 \\
3 & 10 & 0.0190 & 3.78 \\
4 & 10 & 0.0140 & 2.60 \\
5 & 10 & 0.0080 & 1.34 \\
6 & 10 & 0 & 0 \\
7 & 10 & 0.0020 & 0.36 \\
8 & 10 & 0.0110 & 2.09 \\
9 & 10 & 0.0017 & 0.34 \\
10 & 10 & 0.0054 & 1.12 \\
11 & 10 & 0.0012 & 0.19 \\
12 & 10 & 0.0270 & 4.46 \\
13 & 10 & 0.0360 & 5.45 \\
\hline
\end{tabular}

and confirmed that immobilization of BCP within the porous silica matrix in the presence of surfactant molecules does not diminish the activity of BCP molecules.

3.11. Effect of Interferences on BCP/SDS Thin Film Stability. The BCP/SDS thin film was immersed in different solutions of $1 \mathrm{M}$ concentration including hydrochloric acid, acetic acid, ammonium hydroxide, sodium carbonate, potassium chloride, and sodium hydroxide, then washed with water and neutralized at pH 7 (Figure 23). The UV/Vis spectra showed that the film is stable in different types of solutions.

\subsection{Effect of Life Time on BCP/SDS Thin Film Stability.} The lifetime of BCP/SDS thin films was studied at sixmonth time period. The sensors were stored at ambient temperature in dried conditions. Almost, no leaching or change in absorbance response was shown for these films (Figure 24). So these films are considered to be very stable at long time periods.

3.13. Effect of Multilayer Thin Film Coating. Coating of the glass slides with multilayers of silica immobilized with $\mathrm{BCP} / \mathrm{SDS}$ at the same preparation conditions was performed. It is obvious that the absorbance of the BCP/SDS thin film increases as the number of layers increases (Figure 25). The percentages of signal increment were $34.3 \%$ and $67.7 \%$ for double and triple layers, respectively, compared with single layer. On washing, the single layer of BCP/SDS thin film showed lower leaching than both double and triple layers (Figure 26). The leaching percentages were 1.5\%, 4.1\%, and $13.4 \%$ for single, double, and triple layer, respectively. The order of leaching is arranged as follows:

$$
\text { Single layer }<\text { double layer }<\text { Triple layer. }
$$

3.14. Polarized Light Microscopy (PLM). Several photographs were taken by crossed polarized light microscope for thin films of free silica, immobilized $\mathrm{BCP} /$ without surfactant, immobilized BCP/SDS, immobilized BCP/CTAB, and immobilized $\mathrm{BCP} / \mathrm{TX}-100$ in order to examine the nature of interaction between BCP, silica, and surfactants. Figures 27(a) and 27(b) involve the free silica and immobilized $\mathrm{BCP} /$ without surfactant, respectively. From these figures, it is clear that the particle size distribution is wider in the free silica, while in presence of BCP, the modified particles become more uniform and smaller in size. The effect of different surfactants on the modification and distribution of the particles was also observed. Figures $27(\mathrm{c}), 27(\mathrm{~d})$, and 27(e) involve immobilized BCP/SDS, BCP/CTAB, and $\mathrm{BCP} / \mathrm{TX}-100$ respectively. From these figures, it is shown that there is an increase in the number of particles than the free immobilized BCP. Also, the size of the particles becomes smaller and more uniform. This behavior is due to the electrostatic interaction of surfactant with $\mathrm{BCP}$ molecules. This was supported by the increase of absorption intensities of the bands around $\lambda_{\max }=435 \mathrm{~nm}$ (Figure 1) as the hydrophobic part of surfactant participates in the acceleration of the association of the particles which lead to increase of its stability. From the photograph of the immobilized BCP/SDS (Figure 27(c)), the SDS surfactant has more effect on improvement and modification of the particles than CTAB and TX-100, (Figures 27(d) and 27(e), resp.).

\section{Conclusion}

A monolithic BCP immobilized thin films were prepared by spin-coating technique in the presence of cationic CTAB, anionic SDS, and nonionic TX-100 surfactants. The sol-gel process was used to prepare thin films deposited on glass slides, which involves hydrolysis and polycondensation of tetraethylorthosilicate in presence of catalyst, BCP indicator, and surfactant. The best thin film obtained was the BCP/SDS which showed high UV-Vis absorbance and lowest leaching. BCP molecules were properly accommodated within silica network pores when the thin films were dried at $80^{\circ} \mathrm{C}$ and well interacted when surfactants were used. These sensors were found to be very sensitive for $\mathrm{pH}$ change as the BCP retained its structure on immobilization. The BCP thin films show high stability at long time intervals and different $\mathrm{pH}$ values. The presence of surfactants has improved silica network and increased its surface area.

\section{Acknowledgment}

The authors thank the Islamic University of Gaza for financial support.

\section{References}

[1] W. Jin and J. D. Brennan, "Properties and applications of proteins encapsulated within sol-gel derived materials," Analytica Chimica Acta, vol. 461, no. 1, pp. 1-36, 2002.

[2] C. J. Brinker and G. W. Scherer, Sol-Gel Science, Academic Press, New York, NY, USA, 1990. 
[3] J. Livage, T. Coradin, and C. Roux, "Encapsulation of biomolecules in silica gels," Journal of Physics Condensed Matter, vol. 13, no. 33, pp. R673-R691, 2001.

[4] I. Gill and A. Ballesteros, "Bioencapsulation within synthetic polymers (Part 1): sol-gel encapsulated biologicals," Trends in Biotechnology, vol. 18, no. 7, pp. 282-296, 2000.

[5] X. Chen and S. Dong, "Sol-gel-derived titanium oxide/copolymer composite based glucose biosensor," Biosensors and Bioelectronics, vol. 18, no. 8, pp. 999-1004, 2003.

[6] X. Chen, Y. Hu, and G. S. Wilson, "Glucose microbiosensor based on alumina sol-gel matrix/electropolymerized composite membrane," Biosensors and Bioelectronics, vol. 17, no. 1112, pp. 1005-1013, 2002.

[7] A. F. Hsu, T. A. Foglia, and S. Shen, "Immobilization of Pseudomonas cepacia lipase in a phyllosilicate sol-gel matrix: effectiveness as a biocatalyst," Biotechnology and Applied Biochemistry, vol. 31, no. 3, pp. 179-183, 2000.

[8] R. Zusman, C. Rottman, M. Ottolenghi, and D. Avnir, "Doped sol-gel glasses as chemical sensors," Journal of Non-Crystalline Solids, vol. 122, no. 1, pp. 107-109, 1990.

[9] L. L. Hench and J. K. West, "The sol-gel process," Chemical Reviews, vol. 90, no. 1, pp. 33-72, 1990.

[10] S. Sakka, in Sol-gel technology for thin films, fibers, electronics, and specialty shapes, L. C. Klein, Ed., p. 140, Noyes Publications, Park Ridge, NJ, USA, 1988.

[11] R. D. Wilken, "Mercury analysis: a special example of species analysis," Fresenius' Journal of Analytical Chemistry, vol. 342, no. 10, pp. 795-801, 1992.

[12] J. D. Wright and N. A. J. M. Sommerdijk, Sol-Gel Materials: Chemistry and Applications, Gordon and Breach Science, Amsterdam, The Netherlands, 2001.

[13] J. Samuel, A. Strinkovski, S. Shalom et al., "Miniaturization of organically doped sol-gel materials: a microns-size fluorescent pH sensor," Materials Letters, vol. 21, no. 5-6, pp. 431-434, 1994.

[14] F. R. Zaggout, "Entrapment of phenol red $\mathrm{pH}$ indicator into a sol-gel matrix," Materials Letters, vol. 60, no. 8, pp. 1026-1030, 2006.

[15] I. M. El-Nahhal, S. M. Zourab, and N. M. El-Ashgar, "Encapsulation of phenolphthalein $\mathrm{pH}$-indicator into a sol-gel matrix," Journal of Dispersion Science and Technology, vol. 22, no. 6, pp. 583-590, 2001.

[16] Y. Dimitriev, Y. Ivanova, and R. Iordanova, "History of sol-gel science and technology," Journal of the University of Chemical Technology and Metallurgy, vol. 43, no. 2, pp. 181-192, 2008.

[17] O. S. Wolfbeis, N. V. Rodriguez, and T. Werner, "LEDcompatible fluorosensor for measurement of near-neutral $\mathrm{pH}$ values," Mikrochimica Acta, vol. 108, no. 3-6, pp. 133-141, 1992.

[18] L. A. Saari and W. R. Seitz, "pH sensor based on immobilized fluoresceinamine," Analytical Chemistry, vol. 54, no. 4, pp. 821-823, 1982.

[19] A. Lobnik, I. Oehme, I. Murkovic, and O. S. Wolfbeis, "pH optical sensors based on sol-gels: chemical doping versus covalent immobilization," Analytica Chimica Acta, vol. 367, no. 1-3, pp. 159-165, 1998.

[20] L. M. Ellerby, C. R. Nishida, F. Nishida et al., "Encapsulation of proteins in transparent porous silicate glasses prepared by the sol-gel method," Science, vol. 255, no. 5048, pp. 1113-1115, 1992.

[21] G. Wirnsberger, P. Yang, B. J. Scott, B. F. Chmelka, and G. D. Stucky, "Mesostructured materials for optical applications: from low-k dielectrics to sensors and lasers," Spectrochimica Acta Part A, vol. 57, no. 10, pp. 2049-2060, 2001.

[22] I. M. El-Nahhal, S. M. Zourab, F. S. Kodeh, and A. AlBawab, "Behaviour of phenol red $\mathrm{pH}$-sensors in the presence of different surfactants using the sol-gel process," International Journal of Environmental Analytical Chemistry, vol. 90, no. 8, pp. 644-656, 2010.

[23] G. G. Guilbality, Analytical Uses of Immobilized Enzymes, Marcel Dekker, New York, NY, USA, 1989. 


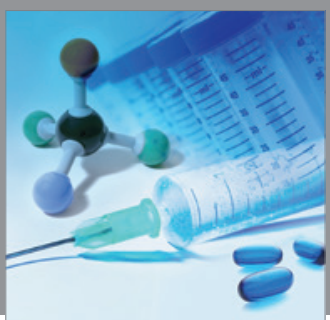

International Journal of

Medicinal Chemistry

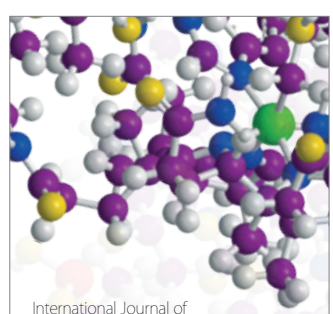

Carbohydrate Chemistry

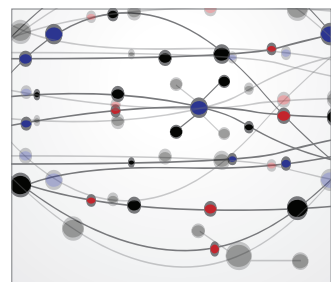

The Scientific World Journal
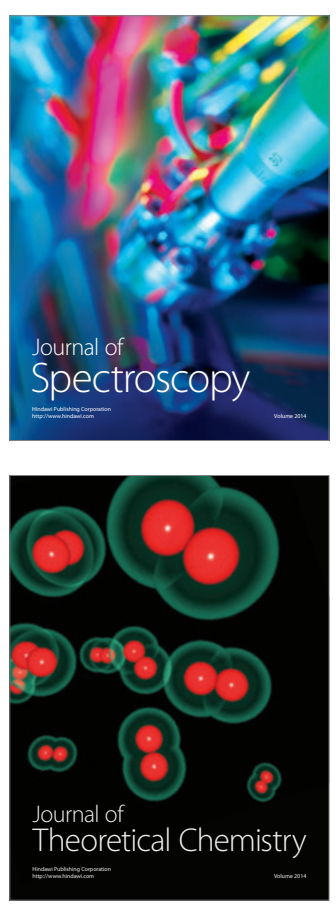
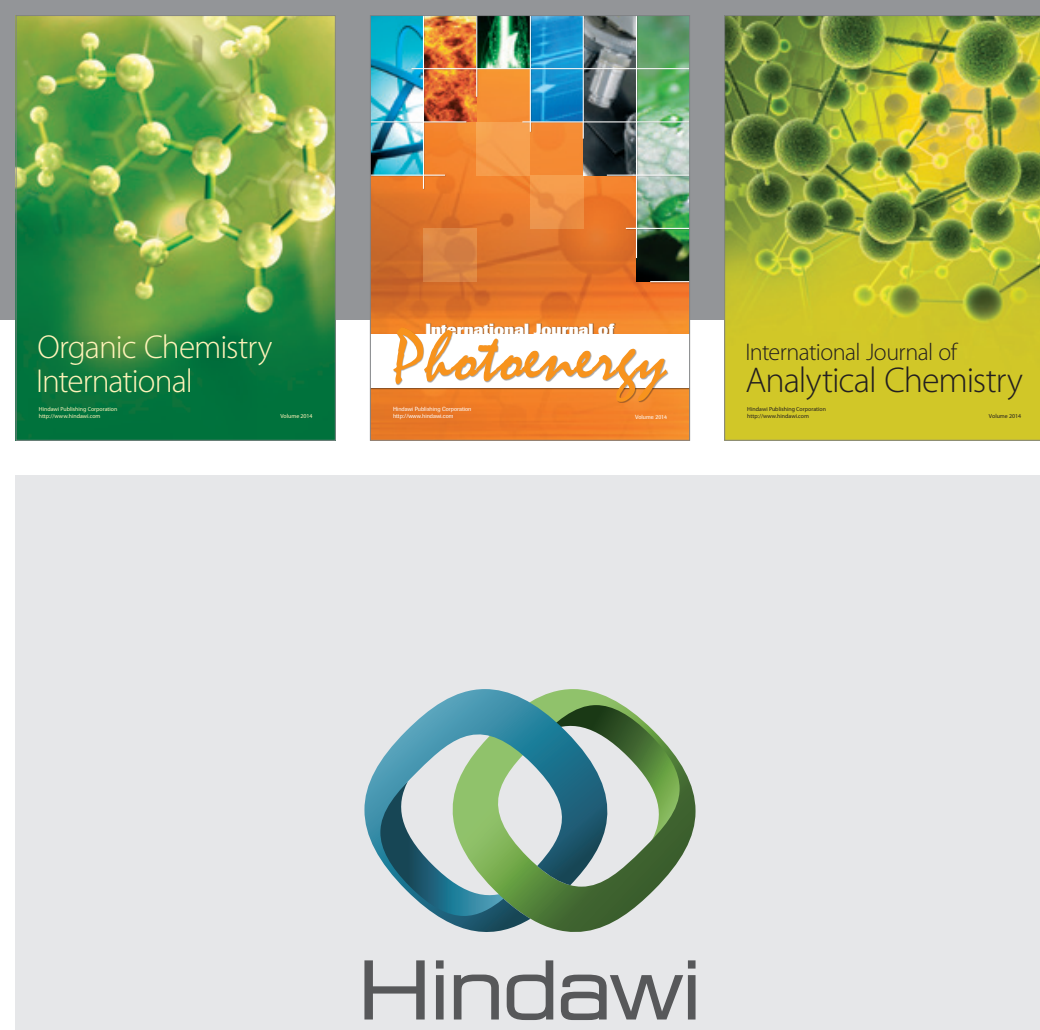

Submit your manuscripts at

http://www.hindawi.com
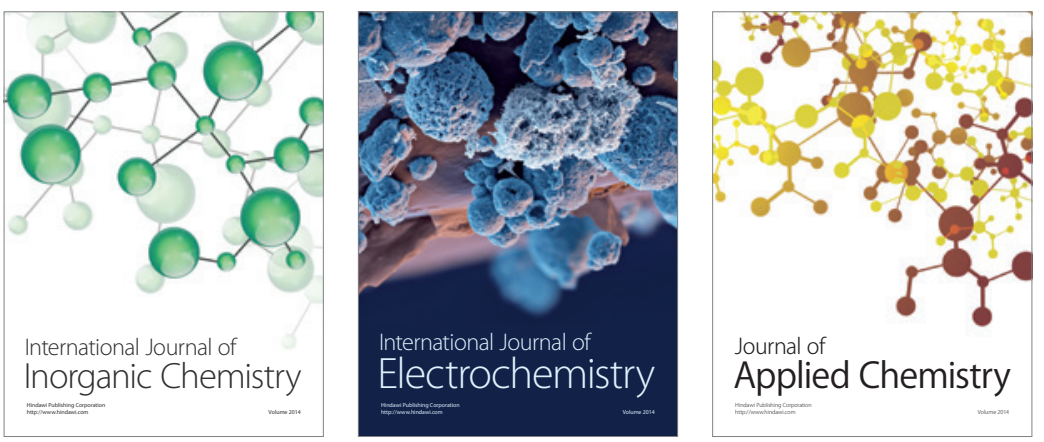

Journal of

Applied Chemistry
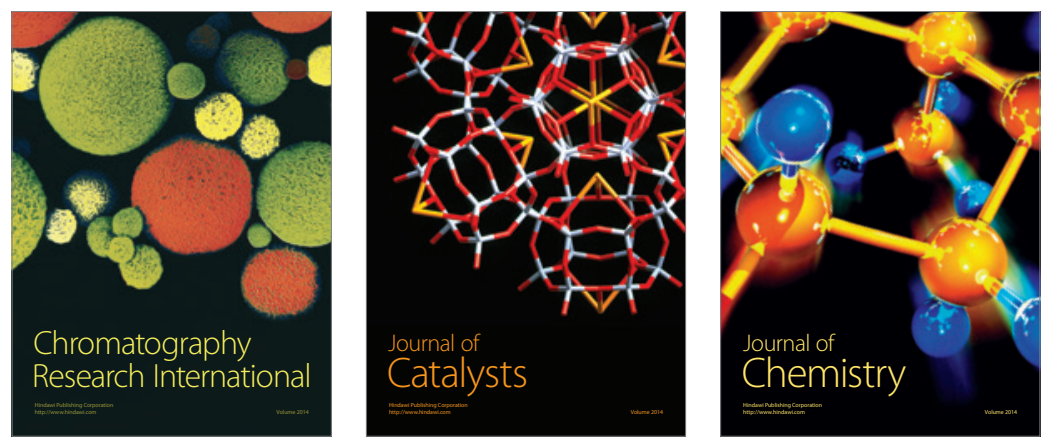
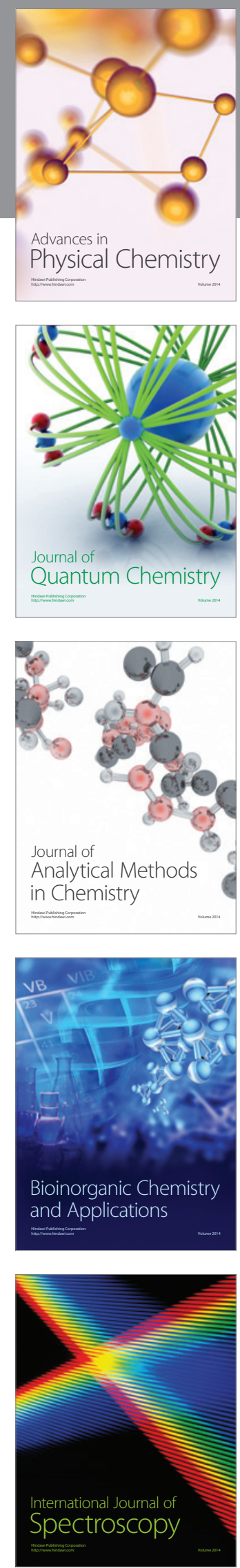